\title{
An Analysis on Impact of Exchange Rate on Nifty and S \& P Sensex
}

\author{
G. S. Jayesh
}

\begin{abstract}
In the last two decades, the developments happened in India have led to an interdependency between the stock market and exchange rate markets. The present study focuses on understanding the impact of the foreign exchange rate and the stock market interdependency. The indices NIFTY and SENSEX define major movements in the stock market hence they gain importance in studying. Also, the technical analysis has been done for the Indices to study the performance of stock. The results obtained from the study will facilitate the decision making of the investors.
\end{abstract}

Index Terms: Foreign Exchange, Nifty, Stock Market, Sensex

\section{INTRODUCTION}

Financial markets are the centers and arrangements that make it possible to buy and sell financial assets, such as financial instruments, claims and services. The National Stock Exchange of India Ltd. (NSE) is the leading stock exchange in India and the second largest in the world by no of trades in equity shares. NSE launched electronic screenbased trading in 1994, derivatives trading (in the form of index futures) and internet trading in 2000, which were each the first of its kind in India. The Bombay Stock Exchange (BSE) is Asia's oldest stock exchange. Based in Mumbai, India, was established in 1875 as the Native Share \& Stock Brokers' Association. Its benchmark index, the Sensitive Index (Sensex) was launched in 1986.

The NIFTY 50 index is National Stock Exchange of India's benchmark broad based stock market index for the Indian equity market. It represents the weighted average of 50 Indian company stocks in 12 sectors and is one of the two main stock indices used in India. The S\&P SENSEX is a free - float market-weighted stock market index of 30 well-established and financially sound companies listed on Bombay Stock Exchange these are prominent indices in India. The present study focuses on effect of exchange rate on Nifty 50 and S\&P Sensex by comparative analysis using regression and correlation for a period of one year (i.e. January2018 to December2018).

\section{OBJECTIVES}

- To understand the general trend of indices of Nifty 50 and S\&P Sensex

- To study the relationship between Exchange rate (INR/USD) with NIFTY 50 and S\&P Sensex

- To study the Impact of Exchange rate on NIFTY 50

Revised Manuscript Received on July 09, 2019.

Dr. G. S. Jayesh, Asst Professor, Department of Business Administration, Government Arts and Science College, Peravurani, Tamil Nadu and S\&P SENSEX

- To perform Technical analysis on NIFTY 50 and S\&PSENSEX

\section{REVIEW OF LITERATURE}

- Tran Mong Uyen Ngan (2016) studied the relationship between foreign exchange rate and stock price and found out that this relationship is a point of interest not only for board of directors but also the investors.

- Deepti Gulati and Monika Kakhani (2016),in their study performed Granger causality test to concluded that SENSEX and NIFTY do not have a two way relationship with exchange rate

- Daan Struyven (2015) studied the competition of BSE and NSE and compared both in various aspects and concluded that NSE surpassed on equity segment.

- N.S.Nataraja , Ganesh.Let al.(2014),studied the linkage of CNX Nifty bank Nifty and foreign exchange rate. It showed that there is a negative relationship.

- Vandana Kotai(2013),examined the behavior of the five international currency pairs (INR/USD, JPY/USD, EURO/USD, GBP/USD, and $\mathrm{CNY} / \mathrm{USD})$. She observed that Indian currency is relatively volatile than other currencies.

- Mr. K.S.Venkateswara Kumar, Prof. V.Rama Devi (2012) , proved with their analysis that there is a strong correlation between Exchange rate and SENSEX. They have shown that the relation is positive.

- Ohan Laximi chand Rambhia, and Mayank Joshipura (2012) have studied the phenomenon of lottery effect. The results found that Indian markets are similar to other countries and low volatility stocks give a higher absolute return over a longer period.

- Dr. Gaurav Agrawal (2010) analyzed the relationship between Nifty returns and Indian rupee-US Dollar Exchange Rates. In this study, it was found that Nifty returns as well as Exchange Rates were nonnormally distributed. Through unit root test, it was also established that both the time series. Exchange rate and Nifty returns, were stationary at the level form itself. Correlation between Nifty returns and 
Exchange Rates was found to be negative.

\section{RESEARCH METHODOLOGY}

The methodology used was of quantitative in nature and was aimed at depicting the impact of exchange rate on the stock market. The secondary data was collected from NSE, BSE and exchangerate.com websites.

DATA ANALYSIS, TOOLS AND TECHNIQUES USES

- The basic mathematical tools on MS Excel were used for the analysis of quantitative data. The data was analyzed using the five tools of technical analysis.

- 10- Day Simple Moving Average

- Exponential Moving Average(EMA)

- Technical analysis Rate of Change(ROC)

- Relative Strength Index(RSI)

- Moving Average Convergence and Divergence(MACD)

Also linear regression analysis was do net opredict the dependent variable with independent variable. Correlation analysis was also done between dependent (NIFTY\& SENSEX) and independent (Exchange rate) variable.

\section{DATA ANALYSIS}

The main contribution of this paper is to extend their search on technical analysis and regression analysis of Exchange rate (INR/USD), Nifty 50 and S\&P Sensex Index of NSE and then analyze the relationship and Impact of Exchange rate on Nifty 50 and S\&P Sensex using the five important tools of technical analysis. The investors have several tools to assess the Market. One of the miss an approach knows as Technical Analysis. Using this method, investors can get a better understanding of the market sentiment isolate significant trends in the market. This data can be used to make more educated predictions and wiser investors. The use of technical analysis is a widespread and persistent phenomenon which is highly influential in the decision making of foreign exchange professionals. Trading rules based on technical analysis have proved to be capable of providing valuable economic signals and to provide attractive returns.

\section{Technical Analysis of Nifty 50and S\&P Sensex} Analysis of Nifty 50index

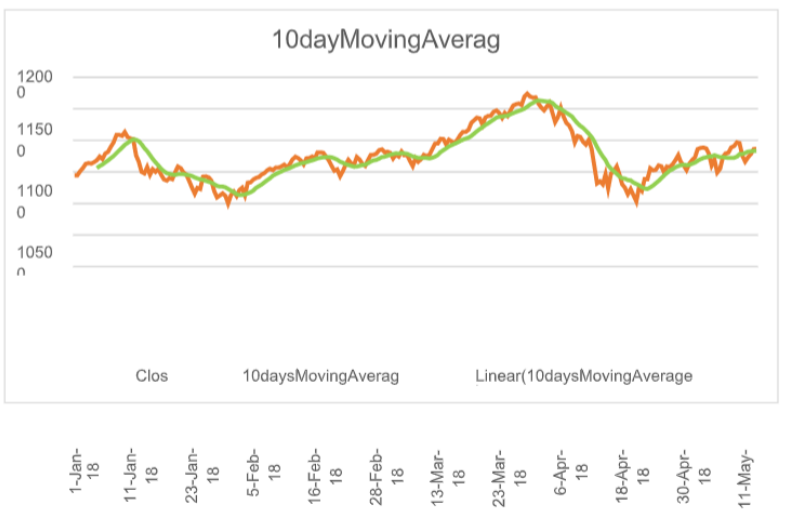

Graph 4.1: 10- Day Moving Average

\section{Interpretation:}

- It is proved from the above graph that the prices of Nifty50 move within a narrow range over a period of one year, i.e., from Jan 2018 to Dec 2018 indicating a flat trend.
- Generally flat trend lines suggest that there have not been many fluctuations in the prices.

- In the initial months of the year 2018, the prices were a bit low indicating an uptrend in the market which implies a buy signal to the investors

- In the mid of 2018, a drastic decrease was observed in the closing prices of Nifty 50 and continued to be a downtrend till the month of April 2018, where the shares were majorly sold by the investors and may incur losses.

- As roved from the above graph that in the month of August and September 2018 the rice is crossing above the moving average which indicates that the market is bull is hand thereafter the close price and moving average is sloping downwards in the month of October which indicates that the prices have been falling in the market.

- In the month of November 2018 there is a slight increase and the reason for this is due to rise in the prices, indicating a bullish trend.

- There as on in the prices further is because of increase in the demand, easing trade war tensions, gain in rupee value, comeback by FPIs, selective buy in gets.

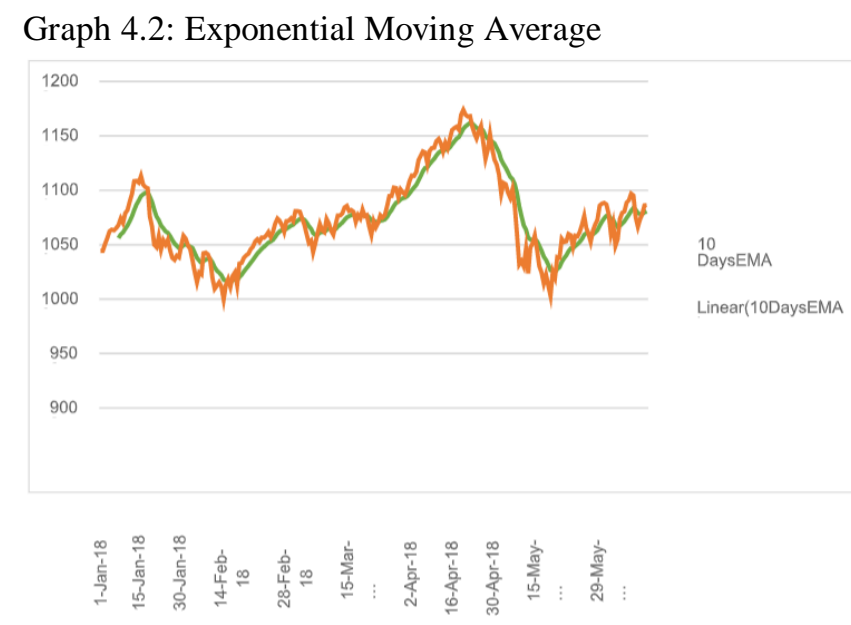

Interpretation

- A lot of fluctuations can be observed in prices. But primary trend of the market has been showing an upward trend. It is known that the Exponential Moving Average has an advantage of being quicker to respond to price fluctuations than a simple moving average.

- When the EMA rises, the strategy of buying may be adopted when prices dip near or just below the EMA. When the EMA falls, it may be considered as a signal to sell when prices rally towards or just above the EMA. In the above graph, in the month of July 2018, it shows an uptrend movement indicating a bullish market.

- Whereas, in the month of September 2018, a downward movement is orved in the share prices, implying a bearish market which indicates a sell signal.

- A rising EMA generally tends to support the price action, while a 
falling EMA (as the above case) is tends to provide resistance to price action. This reinforces the strategy of buying when the price is near the rising EMA and selling when the price is near the falling EMA.

- In the above graph, its orved that the support was orved majorly in the month of July, 2018 around 10500 points. Resistance was orved in the month of October and November 2018 at around 10000 points.

- On 31st December 2018, 1 USD is 69.7158 INR, which is greater than the price as on 31st December 2018 that is 63.8819 INR per USD

- From the above chart, its orved that in the month of March and September, 2018 the price line is below the 10-Day EMA which indicates that the market is bearish.

- In the month of Jan and July, the price line has slightly moved above the 10-day EMA line indicating a bullish trend.

- In the month of October the price line has again come down which is below the MEA line indicating a bearish market which is there by understood that the EMA is not responding faster to the price movements.

- In the month of July, the price line has drastically crossed the EMA line which is above the EMA line which means there is a bullish trend and the EMA is here is responding faster to the price movements.

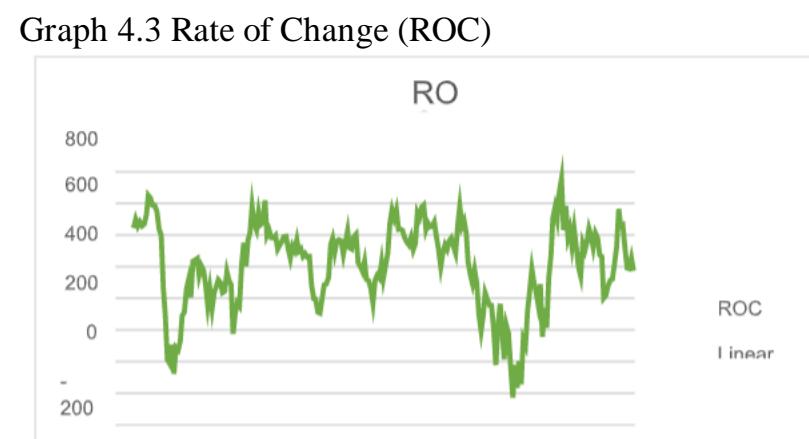

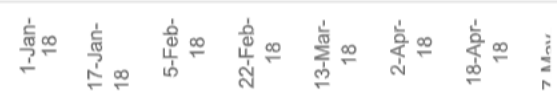

\section{Interpretation}

- The ROC values oscillate across the zero line. The graph above indicates an downward crossing (i.e., from above to below the zero line) which signals a selling opportunity.

- In general, prices rise as long as the Rate-of-Change remains positive. Conversely, prices fall when the Rate-of-Change is negative. The positive values indicate upward buying pressure while the negative values indicate selling pressure. In the above graph, the ROC reached its highest point at 600 points in the month of November, where shares were overbought. This indicates a selling opportunity.

- In a ROC chart, the overbought zone is above the zero line and the oversold zone is below the zero line. The above graph shows that shares were majorly oversold in the month of February and October at -800 points. It is witnessed that the momentum reached its lowest point in October signaling a buying opportunity.
- From February to March, it is orved that the ROC line lies on the zero line where the decision is left indifferent to the investors. From May to July, we see that the ROC line lies above the zero line or below the zero line.

- From the above chart in the month of September, the ROC is below the zero-line indicating over's old zone. Compared to rest of the months it is almost below 800 points which indicates that it is trading below its intrinsic value i.e., the price is below its intrinsic value.

- In the month of November, the ROC is above the zero line and has reached its highest point that is 600 points compared to rest of the months. The reason why it is overbought because the price is higher than its intrinsic value.

Graph 4.4 Relative Strength Index (RSI)

$$
10 \text { Day RSI }
$$

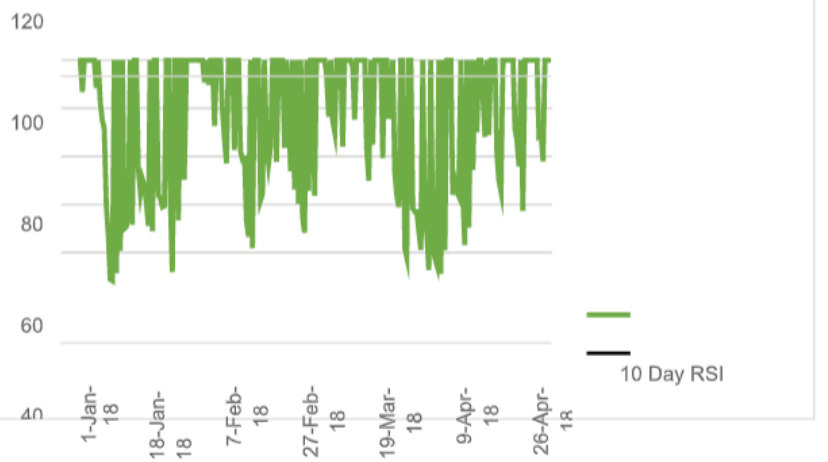

\section{Interpretation}

- The trend line in the above chart implies an upward movement and downward movement in the share prices of the companies traded on Nifty50.

- Relative Strength Index values range from 0 to 100. In general, RSI values above 70 are considered to denote overbought condition and values below 30 are considered to denote oversold condition.

- During few months, RSI of Nifty indices reached its highest point which is above 70 implying an overbought condition. This signals a selling opportunity as RSI has crossed 70 from above to below and continued to fall.

- During February, April, and October, it is orved that the RSI has reached its lowest point which is below 30 indicating an oversold situation. This implies a buying signal because the RSI has crossed the 30 line from below to above.

- An uptrend can be inferred if the RSI is above 50. If RSI is below 50, then a downtrend can be expected. In the graph above, there is lot of fluctuations but when orved carefully there is a bearish divergence of prices.

- From the above chart there are many fluctuations seen but the RSI line is above 70 for most of the months and is at 100 which is constant and thereby it didn't increase further because the RSI indicator can remaining "overbought" territory for extended periods as far as the Nifty indices is in an uptrend

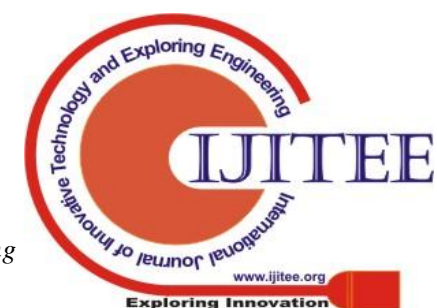


- In the month of February, April, June, July, September, October, November the RSI was below 30 on those particular months as we can orve the above the chart there is an immediate drastic increase in the RSI in the remaining month which indicates that it has reached the overbought zone.

- In the month of February, May and December the RSI is near 50 because usually during a downward trend the RSI would peak near the $50 \%$ level rather than $70 \%$, which could be used by investors to more reliably signal bearish conditions.

Graph 4.5: Moving Average Convergence and Divergence (MACD)

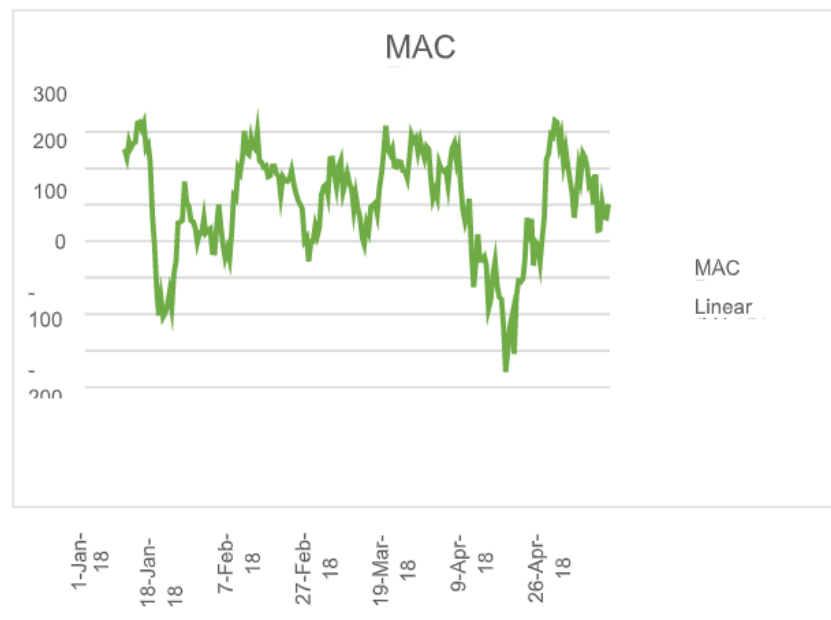

Interpretation

- The MACD line oscillates above and below the zero line, in general. In the above graph, the MACD line moves below the zero line from above where the trend can be said to have turned bearish. This indicates a selling opportunity.

- Positive MACD indicates that the 10-day EMA is above the 20-day EMA. (10-day EMA and 20-day EMA have been calculated for the purpose of this study). Positive values increase as the shorter EMA diverges further from the longer EMA. This means upside momentum is increasing. The MACD was orved at its highest point in the month of February and November at 200points.

- Negative MACD values indicate that the 10-day EMA is below the 20-dayEMA.

- Negative values increase as the shorter EMA diverges further below the longer EMA. This means downside momentum is increasing. MACD reached its lowest point at 500 in the month of October2018.

- The MACD will remain positive as long as there is a sustained uptrend. The MACD will remain negative when there is a sustained downtrend.

- In the above graph, a bullish divergence is orved which is formed as share prices traded in the nifty indices recorded a lower low and the MACD formed a higher low.

- In the month of May and August, the MACD has rose dramatically where the shorter moving average pulled away from the longer-term moving average. This is a signal that there was a huge investment and shares were overbought and will soon return to normal levels.

- While calculating MACD on excel 10-day EMA and 20-day EMA values are calculated and to give the value of MACD 10-day EMA- 20-day EMA is done to get the MACD values and thereafter using only the MACD values a graph is inserted which is why there is no graph line which indicates 10-day EMA and 20-dayEMA.

(b) Analysis of S\&P Sensex

Graph 4.6: 10- Day Moving Average

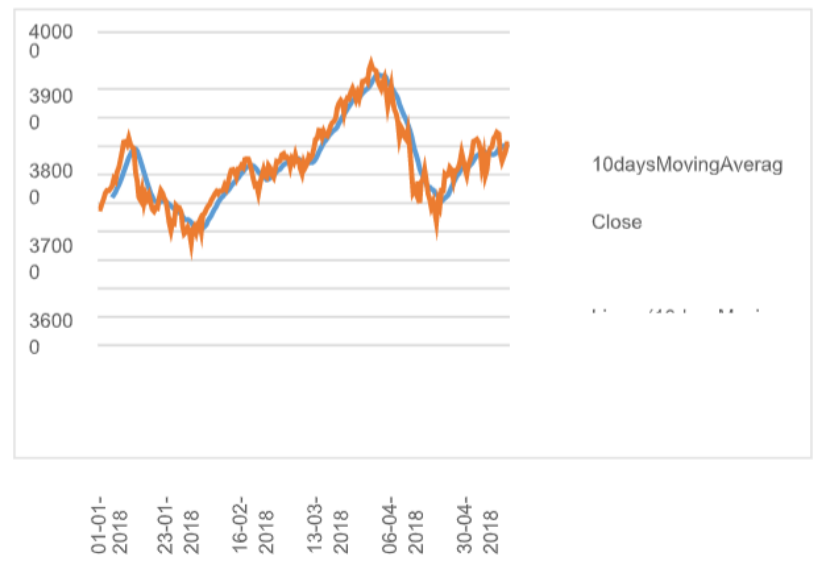

\section{Interpretation}

- The above graph shows that the prices of Sensex indices have increase do vera period of one year indicating a bullish trend which signals buying opportunity.

- It is orved that the moving average clings to the prices and represents their movements better than a straight line and, at the same time, soothes away the occasional erratic price. In the month of August, the price line crosses above the moving average line which indicates a bullish break out ahead.

- In the month of August and September, the moving average line has reached its highest point at 39000 where the prices of shares traded were very high than that of any other months during the year. Then a correction has in the trend which implies a bearish trend that signals selling opportunity.

- In the month of June, July and August 2018, the prices in Sensex indices have really increased after a downtrend (as per the above graph). The downtrend was caused due to the following reasons:

- Market sentiment: It took a beating following sharp losses in other Asian markets which was driven by a record-loss on Wall Street after investor worries peaked over raising US borrowing costs.

- Investors also turned cautious ahead of the RBI policy meet, as they feel that repo rate might be increased amid inflation concerns. Repo rate is the rate at which the central banks lend short term money to commercial banks.

- RBI monetary policy meeting, when rupee depreciated by 29 paise to 64.36 against the dollar.

- Budget proposals to tax equities with a global sell-off, where investors lost

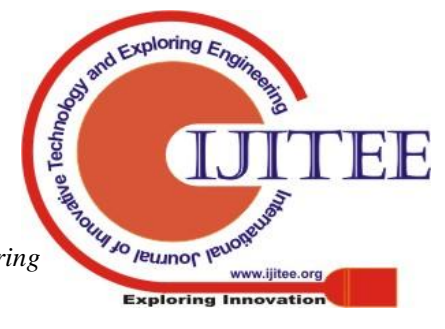


a whopping Rs 9.6 laks crore in three days.

- $\quad$ Strong selling pressure dragged down all the sensex indices.

- However, in the months of February and September 2018 , a downward movement has been orved which indicates a selling signal.

- As this is the case of an uptrend, a 5-day moving average may act as a support level.

Graph 4.7: Exponential Moving Average(EMA)

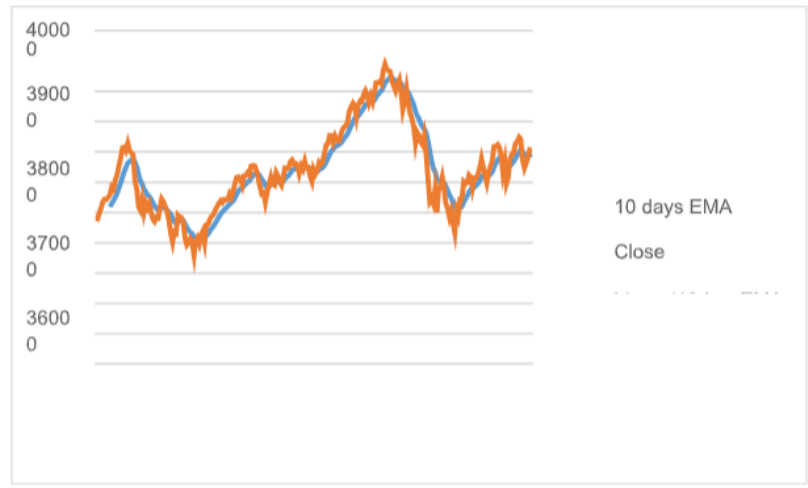

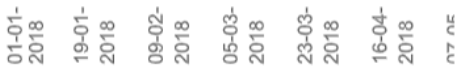 \\ Interpretation}

- From the above graph, it is orved that the primary trend of the market has been upward. As the EMA rise over a period of one year, the strategy of buying may be adopted when prices dip near or just below the EMA.

- When the price crosses an EMA line, traders often view the cross as a sign of price trend reversal. It is advisable to enter buy orders when the short-term EMA crosses above the long-term EMA or enter sell orders when the short-term EMA crosses below the long-term EMA.

- In the month of August and September, a drastic decrease in the share prices of Stocks traded on Sensex indices is orved from the above graph. It shows a downward movement in the EMA line indicating a bearish trend.

- Here, support was established in the month of August. In the month of November, returned to support and formed a low around 33000 points. Resistance was then established in the month of April and December and at around 35000points.

\section{Graph4.8: Rate of Change(ROC)}

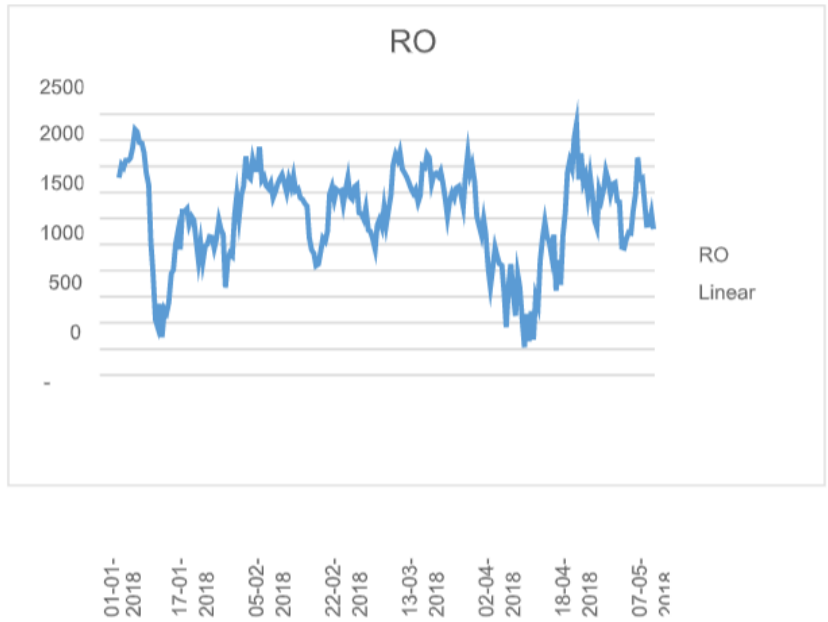

Interpretation:

The ROC graph above indicates an downward crossing (i.e., from above to below the zero line) which signals a selling opportunity.

- When momentum increases, the ROC oscillator moves from negative to above the zero line and when momentum decreases, the ROC oscillator moves from positive and above the zero-line to negative. An upward surge in the Rate-of Change reflects a sharp price advance. A downward plunge indicates a steep price decline.

- In general, it is advisable to buy a commodity that is oversold and sell a commodity that is overbought. From the graph, it is inferred that the ROC reached its highest point in February and November 2018 at 1500 points where the shares were overbought. This signals a selling opportunity.

- The graph shows that shares were oversold during the period of January 2018 and September 2018 as the zone below the zero line is known to be an "oversold" zone. The ROC was orved at its lowest point at -2500 on October. Ideally, an oversold commodity indicates a buying opportunity.

- In the month of November 2018, the ROC has reached its next highest point where the shares were overbought.

- When the Rate of Change indicator surpasses the $+3 \%$ mark, a trader might have interpreted it as having been inadvisable to buy, as prices might have been in an overbought area; in contrast, a trader might be looking for sell signals.

- A market that appears overbought may remain overbought for some time. In fact, extremely overbought/over's old readings usually imply a continuation of the current trend and could signal that a position with the trend may be profitable.

Graph4.9: Relative Strength Index (RSI) 


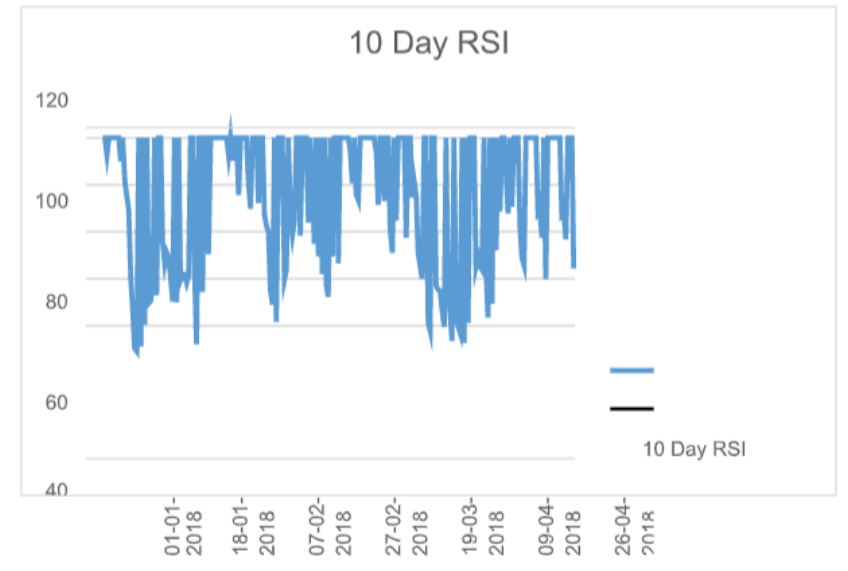

Interpretation

- In the above RSI graph, the trend line implies a downward movement in the prices of share prices in spite of a lot of fluctuations in the market over a period of one year.

- It is orved that in almost all the months of the year, RSI of Sensex reached its highest point which is above 70 implying an overbought condition. This indicates a selling opportunity as RSI has crossed 70 from above to below and continued to fall.

- In the months of February, April, May, June, October, etc, it is orved that the RSI has reached its lowest point which is below 30 indicating an oversold situation. This implies a buying signal because the RSI has crossed the 30 line from below to above.

- In an uptrend or bull market, the RSI tends to remain in the 40 to 90 range with the 40 to 50zone acting as support. During a downtrend or bear market the RSI tends to stay between the 10 to 60 ranges with the $50-60$ zones acting as resistance.

- Generally, decreasing the time period made the RSI more volatile, increasing the number of buy and sell signals substantially. Less risky traders should wait for RSI move above 30 from below 30 to take a position. Aggressive trader's sometimes even take $35 / 65$ as oversold and over bought range.

Graph4.10: Moving Average Convergence and Divergence (MACD)

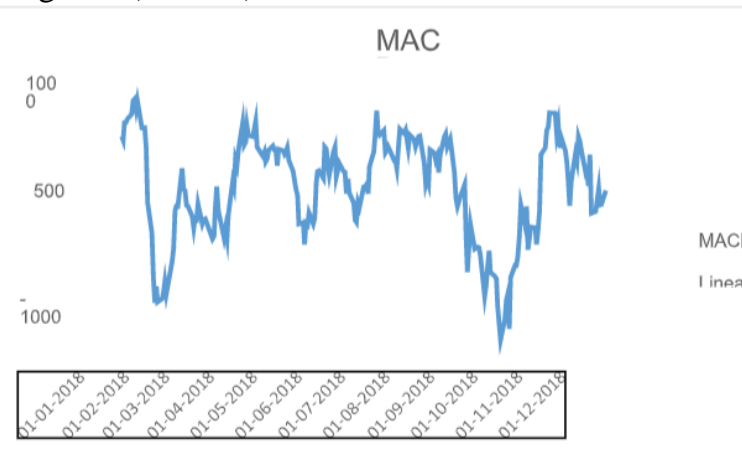

\section{Interpretation}

- In the above graph, the MACD line moves from above the zero line to below where the trend can be said to have turned bearish. This indicates a selling opportunity.

- The MACD was orved at its highest point at 1000 in the month of February and MACD reached its lowest point at -1500 in the month of November.
- A "zero crossovers" event occurs when the MACD series changes sign, that is, the MACDlinecrossesthehorizontalzeroaxis. Thishappenswhent hereisnodifference between the fast and slow EMAs of the price series.

- A change from positive to negative MACD is interpreted as "bearish", and from negative to positive as "bullish". Zero crossovers provide evidence of a change in the direction of a trend but less confirmation of its momentum than a signal line crossover. In the above graph, a change in MACD can be noted from positive to negative in the month of February and March. Negative to positive in the month of April to May.

- If the difference between the two averages is increasing (divergence), this movement favor's the trend continuing.

- While calculating MACD on excel 10-day EMA and 20-day EMA values are calculated and to give the value of MACD 10-day EMA- 20-day EMA is done to get the MACD values and thereafter using only the MACD values a graph is inserted which is why there is no graph line which indicates 10-day EMA and 20-dayEMA.

\section{REGRESSION ANALYSIS:}

Regression analysis generates an equation to describe the statistical relationship between the dependent and independent variable.

In order to find the strength and direction of the variables regression analysis was used. Here,

$\mathrm{Y}=\mathrm{a}+\mathrm{b} * \mathrm{X}+\mathrm{E}$

$Y=$ Nifty 50 and S\&P Sensex $X=$ Exchange rate (US dollar) $\mathrm{a}=$ Constant OR intercept $\mathrm{b}=$ slope of regression

\section{$\mathrm{E}=$ Error}

\section{a) REGRESSION ANALYSIS OF NIFTY50}

For calculating Regression Analysis we need two variables that are Dependent variable and Independent variables. Here Independent Variable is Exchange rate and Dependent Variable is Nifty indices. As it shows the impact of exchange rate on Nifty 50. Assuming that the error term is independent of $\mathrm{X}$ and normally distributed, with zero mean and constant variance. The level of significance between $\mathrm{X}$ and $\mathrm{Y}$ variable is tested at 0.05level. If the P-value is less than 0.05level, we reject the null hypothesis. If the $\mathrm{P}$-value is more than 0.05level, we accept the null hypothesis.

NULL HYPOTHESIS: There is no impact of Exchange rate on Nifty 50

ALTERNATE HYPOTHESIS: There is impact of Exchange rate on Nifty 50. 
Table 4.1

\begin{tabular}{|c|c|c|c|c|}
\hline \multicolumn{5}{|c|}{ Model Summary } \\
\hline Model & $\mathrm{R}$ & $\begin{array}{l}\mathrm{R} \\
\text { Square }\end{array}$ & $\begin{array}{l}\text { Adjusted } \\
\mathrm{R} \\
\text { Square }\end{array}$ & $\begin{array}{l}\text { Std. Error } \\
\text { of the } \\
\text { Estimate }\end{array}$ \\
\hline 1 & $.297^{\mathrm{a}}$ & .088 & .085 & 366.097 \\
\hline
\end{tabular}

a. Predictors: (Constant), Exchange rate

This table gives the values of $\mathrm{R}$ and $\mathrm{R}$ square; here $\mathrm{R}$ denotes simple correlation between Exchange rate (INR/USD) and Nifty 50. I.e. $R=0.297$ which is positively correlated and can be considered as good correlation. $\mathrm{R}$ SQUARE indicates, how much of the dependent variable i.e. Nifty 50 can be explained by the independent variable Exchange rate (INR/USD). In the above model $8 \%$ can be explained.

Table 4.2

ANOVA

\begin{tabular}{|c|c|c|c|c|c|c|}
\hline \multicolumn{2}{|r|}{ Model } & $\begin{array}{l}\text { Sum of } \\
\text { Squares }\end{array}$ & Df & Mean Square & $\mathrm{F}$ & Sig. \\
\hline \multirow[t]{3}{*}{1} & Regression & 3167325.932 & 1 & 3167325.932 & 23.632 & $.000^{\circ}$ \\
\hline & Residual & 32702556.37 & 244 & 134026.8704 & & \\
\hline & Total & 35869882.3 & 245 & & & \\
\hline \multicolumn{7}{|c|}{ a. Dependent variable: Nifty 50} \\
\hline \multicolumn{7}{|c|}{ b. Predictors: (Constant), Exchange rate } \\
\hline
\end{tabular}

The above table indicates that the chosen regression model predicts the outcome variable significantly well. The sig value in the nova table shows the $\mathrm{p}$ value which indicates the statistical significance of the regression model applied, it also shows whether there is impact of Exchange rate on Nifty indices or not. The $\mathrm{P}$ value in the abovetableis 0.000 , which is less than significant level 0.05. $(\mathrm{p}<0.05)$. Thus the Null Hypothesis is not accepted.

Table 4.3

Coefficients

\begin{tabular}{|c|c|c|c|c|}
\hline \multicolumn{5}{|c|}{ Coefficients } \\
\hline Model & $\begin{array}{c}\text { Unstandardized } \\
\text { Coefficients }\end{array}$ & $\begin{array}{c}\text { Standardize } \\
\mathrm{d}\end{array}$ & & \\
\hline
\end{tabular}

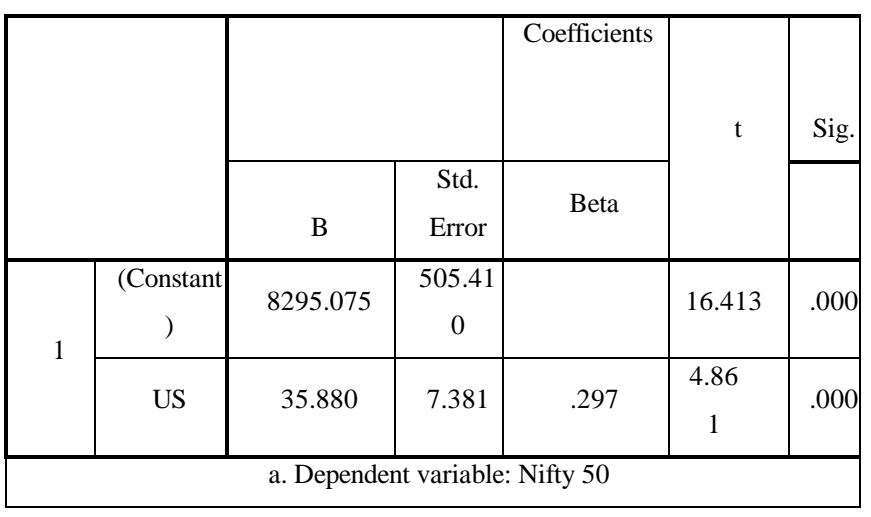

The information in the above table gives the values needed to predict the dependent variable (Impact on Nifty) from the independent variable (Exchange rate). Both the constant and Exchange rate (INR/USD) contribute significantly to the model by looking at significance values in the table.

The regression equation can be presented by taking the values in B column under unstandardized coefficients.

\section{Regression Equation:}

Nifty $50=8295.075+35.880$ (Exchange rate)

Hence Null Hypothesis is not accepted, saying that there is significant impact of Exchange rate on Nifty 50.

\section{REGRESSION ANLYSIS OF S\&PSENSEX:}

Here, Independent Variable is Exchange rate (INR/USD) and Dependent variable is S\&P Sensex, as it shows the impact of Exchange rate on S\&P Sensex. Assuming that the error term is independent of $X$ and normally distributed, with zero mean and constant variance. The level of significance between $\mathrm{X}$ and $\mathrm{Y}$ variable is tested at 0.05 level. If the $\mathrm{P}$ value is less than 0.05 levels, we reject the null hypothesis. If the $\mathrm{P}$ value is more than 0.05 level, we accept the null hypothesis.

NULL HYPOTHESIS: There is no impact of Exchange rate on S\&P Sensex.

ALTERNATIVE HYPOTHESIS: There is impact of Exchange rate on S\&P Sensex.

Table4.4

Model Summary

\begin{tabular}{|l|l|l|l|l|}
\hline Model & $\mathrm{R}$ & $\mathrm{R}$ & $\begin{array}{l}\text { Adjusted R } \\
\text { Square }\end{array}$ & $\begin{array}{l}\text { Std. Error of } \\
\text { the } \\
\end{array}$ \\
& & Square & & Estimate \\
\hline 1 & $.467^{\mathrm{a}}$ & .218 & .214 & 1244.070 \\
\hline \multicolumn{3}{|c|}{ a. Predictors (Constant), Exchange rate } \\
\hline
\end{tabular}

This table gives the values of $\mathrm{R}$ and $\mathrm{R}$ square, here $\mathrm{R}$ denotes simple correlation between Exchange rate and $S \& P$ Sensex i.e. $\mathrm{R}=0.467$ which is positively correlated and can be considered as good correlation. $\mathrm{R}$ square indicates, how much of the dependent variable (Sensex) can be explained by the independent variable (Exchange rate). In the above model $21.8 \%$. can be explained. 
Table 4.5

\begin{tabular}{|c|c|c|c|c|c|}
\hline \multicolumn{6}{|l|}{ ANOVA $^{a}$} \\
\hline Model & $\begin{array}{l}\text { Sum of } \\
\text { Squares }\end{array}$ & $\mathrm{Df}$ & $\begin{array}{l}\text { Mean } \\
\text { Square }\end{array}$ & $\mathrm{F}$ & Sig. \\
\hline $\begin{array}{c}1 \\
\\
n\end{array}$ & $\begin{array}{c}10506984 \\
6.7\end{array}$ & 1 & 105069846.7 & $\begin{array}{c}67.88 \\
7\end{array}$ & $.000^{\circ}$ \\
\hline Residual & $\begin{array}{c}37764111 \\
9.9\end{array}$ & 244 & 1547709.508 & & \\
\hline Total & $\begin{array}{c}48271096 \\
6.6\end{array}$ & 245 & & & \\
\hline \multicolumn{6}{|c|}{$\frac{1}{\text { a. Dependent variable: S\&P Sensex }}$} \\
\hline b. Pred & ctors : (Cons & t), Ex & nge rate & & \\
\hline
\end{tabular}

The above table indicates that the chosen regression model predicts the outcome variable significantly well. The sig value in the ANOVAs table shows the $\mathrm{p}$ value which indicates the statistical significance of the regression model applied, it also shows whether there is impact of Exchange rate (INR/USD) on Sensex or not. The $\mathrm{P}$ value in the above table is 0.000 , which is less than significant level 0.05. $(\mathrm{p}<0.05)$. Thus the Null Hypothesis is not accepted, and say that there is a significant impact of exchange rate on S\&P Sensex.

Table 4.6

\begin{tabular}{|c|c|c|c|c|c|c|}
\hline \multicolumn{7}{|c|}{ Coefficients } \\
\hline \multirow{2}{*}{\multicolumn{2}{|c|}{ Model }} & \multicolumn{2}{|l|}{$\begin{array}{l}\text { Unstandar } \\
\text { dized } \\
\text { Coefficient } \\
\text { s }\end{array}$} & $\begin{array}{c}\text { Standardize } \\
\text { d } \\
\text { Coefficients }\end{array}$ & \multirow{2}{*}{$\mathrm{t}$} & \multirow{2}{*}{ Sig. } \\
\hline & & B & $\begin{array}{l}\text { Std. } \\
\text { Error }\end{array}$ & Beta & & \\
\hline 1 & (Constant) & $\begin{array}{c}21263.76 \\
6\end{array}$ & $\begin{array}{c}1717.48 \\
4\end{array}$ & & 12.381 & .000 \\
\hline & US & 206.656 & 25.082 & .467 & 8.239 & .000 \\
\hline
\end{tabular}

The information in the above table gives the values needed to predict the dependent variable (Sensex) from the independent variable (Exchange rate). Both constant and Exchange rate contribute significantly to the model by looking at significance values.

The regression equation can be presented by taking the values in B column under under standardized coefficients.

A significant regression equation was found i.e. Sensex $=21263.766+1717.484$ (Exchange rate), where $P$ value is less than 0.05 level with an $\mathrm{R}$ of 0.467 and $\mathrm{R}$ square of0.218.
Hence we reject the null hypothesis saying that there is significant impact of Exchange rate on Sensex.

\section{CORRELATION ANALYSIS:}

Correlation is a statistical measure that indicates the extent to which two or more variables fluctuate together. A positive correlation indicates the extent to which those variables increase or decrease inn parallel; a negative correlation indicates the extent to which one variable increases as the other decreases.

Hence this analysis is used to determine the extent to which the change in exchange rate is associated with change in Nifty 50 and S\&P Sensex.

Table 4.7

\begin{tabular}{|c|c|c|c|}
\hline & & NIFTY & US \\
\hline Pearson & NIFTY & 1.000 & .297 \\
\hline Correlation & US & .297 & 1.000 \\
\hline Sig. $\quad$ (1- & NIFTY & & .000 \\
\hline tailed) & US & .000 & \\
\hline \multirow[t]{2}{*}{$\mathrm{N}$} & NIFTY & 246 & 246 \\
\hline & US & 246 & 246 \\
\hline
\end{tabular}

From the above table, it is orved that the correlation between Nifty 50 and Exchange rate (INR/USD) is significant at 0.000 level (1-tailed). The value of correlation is 0.297 which is positive and indicating a good correlation. This implies that Nifty 50 and Exchange rate (INR/USD) are positively correlated to each other. Hence H01 is not accepted, saying there is a statistically significant relationship between Exchange rate and Nifty 50.

Table 4.8

\begin{tabular}{|ll|c|c|}
\hline & & SENSEX & US \\
\hline Pearson & SENSEX & 1.000 & .467 \\
Correlation & US & .467 & 1.000 \\
\hline Sig.(1-ailed) & SENSEX & $\cdot$ & .000 \\
& US & .000 &. \\
\hline $\mathrm{N}$ & SENSEX & 246 & 246 \\
& US & 246 & 246 \\
\hline
\end{tabular}

From the above table, it is orved that the correlation between S\&P Sensex and Exchange rate (INR/USD) is significant at 0.000 level (1-tailed). The value of correlation is 0.467 which is positive and indicating a good correlation. This implies that S\&P Sensex and Exchange rate (INR/USD) are positively correlated to each other. Hence $\mathrm{H} 02$ is not accepted, saying there is a statistically significant relationship between 
Exchange rate and S\&P Sensex.

\section{FINDINGS}

- Trend Analysis of Nifty 50: According to the technical analysis used, it has been found that there is an uptrend in the Nifty 50 close prices as per SMA and EMA whereas ROC and RSI shows a flat trend due to sharp currency depreciation, global uncertainties and inflation, market sentiments, RBI policy related to repo rate, strong selling pressure.

- Trend Analysis of S\&P Sensex: According to the trend analysis used, it has been orved that there was an uptrend in the S\&P Sensex close prices as per SMA and EMA whereas ROC and RSI shows a flat trend due to rupee at low record, rising crude oil prices, RBI policy to tighten NBFC norms.

- Regression Analysis: According to this analysis, its been orved that there was a great impact of Exchange rate (INR/USD) on Nifty 50 and S\&P Sensex. The $\mathrm{p}$ value which is less than 0.05 indicates that the model predicts the outcome variable significantly well and therefore, H03 and $\mathrm{H} 04$ are not accepted. The coefficients for predicting the outcome variable, the coefficients i.e. constant and independent variable (Exchange rate) contribute significantly well to the chosen model because their $\mathrm{P}$ values are less than0.05.Hence the Index of NSE and can be predicted using the linear equation below

Nifty 50 $=8295.075+35.880$ (Exchange rate)

S\&P Sensex = 21263.166+ 1717.484 (Exchange rate)

- It presents on the whole that there is impact of Exchange rate on Nifty50 and S\&P Sensex

- Correlation analysis: It has been orved that there is correlation between Exchange rate (INR/USD) and Nifty 50 which is measured by R i.e., 0.297 which is positive, $\mathrm{R}$ square was 0.088 i.e., $8.8 \%$ can be explained. Also between Exchange rate and S\&P Sensex is measured by $\mathrm{R}=0.467$ which is positive, $\mathrm{R}$ square is 0.218 i.e. $21.8 \%$ can be explained. It means that there is significant relationship between Exchange rate and Nifty 50 and S\&P Sensex as correlation between them is positive.

\section{CONCLUSION}

The study revealed that there is a positive relationship between Exchange rate and S\&P Sensex i.e. strong correlation. The correlation between Exchange rate and Nifty 50 also showed a positive correlation but on a lower side. It indicates that a change in Exchange rate will cause direct change on S\&P Sensex more than change in Nifty 50. Hence a significant regression equation was found to predict the Impact, and it was orved that Impact on Sensex was comparatively higher than the impact of exchange rate on Nifty50. From technical analysis, it's been orved that the trend of S\&P Sensex is affected more due to the fluctuations in the Exchange rate as it showed an uptrend in SMA and EMA compared to the trend on Nifty 50. Also ROC and RSI analysis shows that S\&P Sensex shows a slightly uptrend compared to Nifty 50 which shows a flat trend over a period of one year. (i.e. $1 / \mathrm{Jan} / 2018$ to $1 / \mathrm{Dec} / 2018$ ).

\section{REFERENCES}

1. TRAN MONG UYEN NGAN (2016) Relationship between Foreign Exchange Rate and Stock Price of Commercial Joint Stock Banks: Evidence from Vietnam

2. DEEPTIGULATI,MONIKAKAKHANI,(November2012)RelationshipB etween Stock Market and Foreign Exchange Market in India: An Empirical Study, Volume5, Issue 5

3. Vandana kotai,(2013),IMPACT OF EXCHANGE RATE FLUCTUATION ON STOCK MARKET VOLATILITY-A STUDY TO PREDICT THE ECONOMIC SCENARIO IN INDIA, volume118.

4. Sankaran Venkateshwar,(1991) The Relationship of Indian Stock Market to Other Stock Markets. Indian Economic Journal, Vol. 39, No. 2 (Oct-Dec), p.105-109.

5. Manish.R.Pathak(2013)Stock Market Seasonality: A Study Of The Indian Stock Market (NSE) PARIPEX - Indian Journal of Research Vol 2 Issue 3 $\operatorname{March}(2013)$ 